\title{
A prática de Exposed na internet e a configuração da conduta como abuso de direito
}

\author{
The Exposed practice on the internet and the configuration \\ of conduct as abuse of rights
}

\section{DRIANE FIORENTIN}

Faculdade Meridional - IMED

FranCIELli BRESSAN

Faculdade Meridional - IMED

IURI BOLESINA

Universidade de Santa Cruz do Sul

RESUMo O presente estudo objetiva investigar se a prática de "Exposed" na Internet configura juridicamente violação de direitos alheios, partindo dos estudos acerca do direito constitucional à livre manifestação. Nesse sentido, utilizou-se de uma metodologia de abordagem indutiva, combinada com o método de procedimento monográfico e a técnica de pesquisa em documentação indireta, construindo a pesquisa em três momentos: inicialmente, busca-se conceituar o sentido da palavra "Exposed" e sua aplicação prática nos meios digitais; em segundo lugar, estrutura-se os conceitos doutrinários acerca do direito à livre manifestação e a caracterização do abuso de direito, sendo que, por fim, objetiva-se entender quais práticas de Exposed configuram abuso de direito. Dessa forma, este trabalho foi desenvolvido com o objetivo de compreender as diferentes formas da prática do Exposed e sua possível configuração como abuso de direito. Concluiu-se que é possível exercitar essa conduta sem incorrer em abuso de direito, resguardando informações íntimas acerca do autor dos fatos, mantendo o foco na descrição do ocorrido e permitindo a ocorrência de diálogo nas redes sociais.

Palavras-chave: Direito À privacidade; Exposed; Liberdade de expressĩo.

ABSTRACT This study aims to investigate if the practice of Exposed on the Internet constitutes a legal violation of the rights of others, based on studies on the constitutional right to freedom of expression. In this sense, an inductive approach methodology was used, combined with the monographic procedure method and the indirect documentation research technique, doing the research in 3 moments: First at all, it seeks to conceptualize the meaning of the word "Exposed" and its application in digital practice; at the second place, doctrinal concepts about the right to freedom of expression and the characterization of rights abuses are structured, and finally, the objective is to understand which Exposed practices 
constitute abuse of rights. It was concluded that it is possible to exercise this conduct without incurring an abuse of rights, safeguarding intimate information about the author of the facts, keeping the focus on describing what happened and allowing dialogue to take place on social networks.

Keywords: Right to Privacy; Exposed; Freedom of eXPression.

\section{INTRODUÇÃo}

As discussões envoltas nos confrontos de direitos fundamenteis esbarram em uma nova forma de conflito mediada pelas redes sociais, popularmente chamada de Exposed. A prática consiste na exposição de fatos/acontecimentos que expõem crimes ou comportamentos questionáveis, colocando em debate os limites entre a liberdade de expressão de quem vai relatar o acontecimento e o direito à privacidade da parte exposta no fato narrado. Não escapa dessas tensões o direito à manifestação, uma vez que as discussões se intensificam com as relações no seio da Internet, em especial na rede social Twitter.

A partir disso, buscar-se-á responder o seguinte problema de pesquisa: no que consiste a prática de Exposed e de quais possíveis formas ela pode configurar-se em abuso do direito ou crime? Nesse sentido, buscou-se desenvolver este artigo com o objetivo de promover o debate em torno dos limites instituídos à liberdade de expressão da parte que fará a exposição do acontecimento e a possível violação ao direito de privacidade da parte exposta.

Portanto, propõe-se estruturar o artigo em dois segmentos: de forma inicial, buscar-se-á definir o conceito de Exposed, bem como a forma que essa prática tem sido utilizada nas redes sociais brasileiras. E, por fim, entender se a prática de Exposed pode configurar abuso de direito ou crime.

Para o desenvolvimento da pesquisa, será utilizada a metodologia de abordagem indutiva, considerando que será partido de um ponto específico para então adentrar em um ponto geral, combinado com o método de procedimento monográfico e a técnica de pesquisa de documentação indireta.

\section{BREVE DEFINIÇÃO DE EXPOSED E SUAS POSSÍVIS FORMAS}

Ainda que a palavra "Exposed" não possua uma definição exata nos dicionários brasileiros, a tradução do termo em inglês significa "expor, apresentar, exibir, desmascarar" (SCOTTINI, 2009, p. 235). De acordo com UOL (2020), o termo é "usado nas redes sociais especialmente quando alguém é denunciado por uma ação que antes ninguém sabia".

O Exposed é uma prática de expressão/exibição/exposição de acontecimentos que recentemente ganhou visibilidade nos meios digitais, na qual uma das partes expõe a conduta de outra(s) parte(s) na Internet de forma unilateral. Trata-se, portanto, de uma nova forma de exposição não consentida veiculada por meio das redes sociais.

Tal prática surgiu na Internet em meados de 2015 com o movimento \#MeuAmigoSecreto (UOL, 2020), o qual tratava-se de "uma compilação de relatos e denúncias de situações de machismos (GALILEU, 2015), vivenciadas cotidianamente por mulheres. A 
ideia do movimento era utilizar da corriqueira brincadeira do amigo oculto para revelar os comportamentos inapropriados (quando não criminosos) de pessoas próximas às vítimas (EL PAÍS, 2015).

O cenário se repetiu em 2017 com o movimento \#MeToo, no qual a atriz Alyssa Milano pediu em seu Twitter para que as vítimas de abusos e assédios sexuais utilizassem a hashtag para contar suas histórias (VEJA, 2019). De acordo com a BBC (2018), ao menos meio milhão de pessoas utilizaram da hashtag nas primeiras 24 horas após a postagem de Milano, desencadeando iniciativas que foram além dos 280 caracteres permitidos pelo Twitter.

Desde a criação de um fundo de arrecadação para fornecer amparo legal às vítimas de assédio ou abuso (Time's Up Legal Defense Fund) (BBC, 2018) até o desenvolvimento de protestos pacíficos no Globo de Ouro (EL PAÍS, 2019), são alguns exemplos dos efeitos do movimento \#MeToo e, consequentemente, da prática de Exposed.

O alcance dessa exposição ocorreu em razão do "desenvolvimento da Sociedade em Rede, caracterizada pela instantaneidade dos fluxos além das fronteiras estatais" (SILVA; VIEIRA, 2020, p.117). Ou seja, o avanço das redes sociais possibilitou que a informação (nesse caso a exposição de um fato íntimo) se espalhasse de forma instantânea. Como bem resume Silva e Vieira (2020, p. 117), o Exposed desencadeia tensões que merecem atenção, pois ao passo que evidencia o exercício do direito de liberdade de expressão pela vítima, com o fluxo instantâneo de informações nas redes sociais, impossibilita o desenvolvimento do direito ao contraditório entre as partes, o que resulta em um julgamento antecipado e público dos envolvidos.

Esse tipo de prática, contudo, não necessariamente ocorre sempre da mesma forma ou sobre o mesmo conteúdo, podendo variar de acordo com a intenção do indivíduo que irá fazer a exposição do fato. Nesse sentido, importa destacar que se parte da hipótese que a prática de Exposed busca expor o comportamento inadequado do sujeito e não tão somente o sujeito em si. Isso porque a exposição nas redes sociais de pessoas que não gostam de chimarrão, a título de exemplo, configura, em tese, a prática de Exposed, uma vez que se torna pública uma característica íntima do sujeito, sem, contudo, violar direitos.

Como supracitado, o fato objeto da exposição na maioria das vezes, trata-se de uma situação que ocorreu às escondidas, tendo apenas a pessoa que está realizando o Exposed presenciado, ou, na melhor das hipóteses, pessoas próximas as partes envolvidas. Em relação às provas, na maioria das vezes, tornam-se comprometidas, seja pela forma que ocorreu o fato ou até mesmo pelo tempo passado após sua ocorrência.

Ainda, ressalva-se que o autor do fato poderá tentar silenciar a vítima. Nesse sentido, um dos medos do praticante ao recorrer ao Poder Judiciário está na possível retaliação por parte da pessoa exposta, podendo resultar na retirada da denúncia ou queixa-crime, bem como em uma provável retratação pública pelo Exposed feito.

Tal possibilidade junto à crescente popularidade do movimento, fez com que cada vez mais pessoas recorressem ao apoio dos internautas para o efetivo relato do acontecimento, de forma a expor situações que lhe causavam medo ou até constrangimento. Entretanto, embora tal possibilidade tenha empoderado várias vítimas por meio da liberdade de expressão, a exposição realizada de forma equivocada ou sendo inobservados certos preceitos, podem gerar consequências negativas, como um processo judicial contrário a si. 
O presente trabalho trata de analisar duas formas específicas de exposição, sendo a primeira em relação ao fato, de modo a ocultar as informações em relação ao(s) autor(es) deste, enquanto a segunda, além da exposição do fato, existe também a vinculação de quem foi o responsável.

Quanto à primeira hipótese, o objeto se trata puramente do fato, ou seja, é uma narrativa do que ocorreu, dessa forma, enquadrando-se na dita liberdade de expressão. Contudo, o problema dessa hipótese gira em torno de seu próprio objeto, pois embora a apresentação de provas não seja algo necessário na Internet, a falta da mínima autoria do fato acaba por gerar dúvidas em relação à sua veracidade para certas pessoas. Assim, quem está publicando, muitas vezes, procura juntar elementos que identifiquem o autor do fato como forma de demonstrar que o relato é verdadeiro.

Entende-se, assim, que a segunda hipótese se trata de uma narrativa que compreende além dos fatos, a autoria deste. A problemática nesse sentido ocorre com o uso das informações pessoais de quem foi imputado ao fato, praticando a exposição do indivíduo em uma espécie de busca de "justiça com as próprias mãos". Isso acaba por remeter a uma pura violação aos direitos fundamentais do agente a qual as informações estão sendo imputadas, podendo inclusive resultar em consequências jurídicas à parte expositora, tanto na esfera criminal quanto na seara civil.

Quanto a isso, deve-se sempre estar ciente que tanto a Constituição Federal, assim como o Código Civil e o Código Penal buscam garantir os direitos referentes à honra e a imagem do indivíduo, devendo evitar a prolação de qualquer relato vinculado a uma pessoa específica. Caso exista essa vinculação, o agente pode sentir-se ofendido, principalmente com a ausência de provas, e dar espaço à um processo inclusive no âmbito criminal.

O Código Penal prevê três hipóteses de crimes contra a honra, sendo eles a injúria (art. 140 Código Penal), a calúnia (art. 138 Código Penal) e a difamação (art. 139 Código Penal). No que tange a calúnia, trata-se de um crime imputado ao agente, por exemplo, o estupro. Em relação à difamação, diz respeito a sua honra objetiva, ou seja, a sua reputação, por exemplo, o relato de que o agente deixou de pagar suas contas e é devedor. E por fim, a injúria, a qual está relacionada com a honra subjetiva da pessoa, sendo interpretada como um xingamento.

Além do mais, para tal penalização, o relato pode estar vinculado a informações como o nome, o endereço ou o telefone do agente, bem como as suas fotos. Ainda, o Código Civil também prevê sanções nesse sentido, diferente do âmbito penal, relacionadas à pecúnia. Dessa forma, o relato contendo tais informações poderiam estar ligado aos discursos de ódio, linchamento virtual ou mesmo pessoalmente, com a possibilidade de a vítima do fato do Exposed responder tanto por dano patrimonial ou extrapatrimonial.

Quanto ao dano moral, pode ser entendido como atinente à reputação do exposto perante a sociedade, enquanto o dano material pode estar envolvido em danos efetivos consequentes da exposição, como linchamento ou danos à residência ou lugar de trabalho. Posto isso, antes de publicar efetivamente um Exposed deve-se sempre haver a reflexão se tal ação pode gerar alguma consequência negativa para a vítima do fato.

Ademais, quando se remete ao Exposed é necessário lembrar que se trata de um movimento que surgiu para incentivar a exposição de fatos sofridos pela vítima, centrando 
a vítima e buscando acolhê-la. Nesse sentido, embora, como supracitado, determinados dados devam ser evitados, outros podem ser utilizados de forma a acompanhar os relatos e fundamentos, sem que haja uma efetiva consequência judicial.

Isso significa que provas expostas de forma mais abstrata, mas que mesmo assim mostram-se robustas podem ser utilizadas, como uma referência genérica do autor do fato, mensagens e até mesmo boletins de ocorrência (quando existirem), desde que os dados do agente estejam ocultos.

Da mesma forma, a exposição da história enquanto vítima, figurando principalmente os sentimentos no momento do fato, e, até mesmo, as consequências posteriores ao ocorrido, bem como quais formas buscou para lidar com isso, podem ser mecanismos úteis ao embasamento da exposição virtual.

Sendo assim, ainda que a prática de Exposed possa ocorrer de variadas formas, com o objetivo de delimitar a análise do abuso de direito, a pesquisa será guiada pelas duas formas acima mencionadas.

\section{EXPOSED COMO ABUSO DE DIREITO E COMO EXERCÍCIO REGULAR DE DIREITO}

A Constituição Federal previu em seu artigo $5^{\circ}$, principalmente no inciso $\mathrm{X}$, um rol de direitos fundamentais, garantindo, dentre outras, a inviolabilidade sobre a intimidade, a vida privada, a honra e a imagem das pessoas. Ainda, na hipótese de violação de tais garantias, assegurou o direito à indenização pelo dano material e/ou moral decorrente.

Soma-se à Carta Magna o instituto da Responsabilidade Civil, vertente do Código Civil, no qual em especial os artigos 186 e 187 buscam caracterizar atos ilícitos, de forma a facilitar a reparação em via judicial. Conforme Nader (2016, p. 539), atos ilícitos seriam espécies de fatos jurídicos que se consolidam em acontecimentos que causam modificações ou extinções de relações jurídicas.

Sua caracterização no Código Civil (BRASIL, 2002) aparece por meio dos artigos:

Art. 186. Aquele que, por ação ou omissão voluntária, negligência ou imprudência, violar direito e causar dano a outrem, ainda que exclusivamente moral, comete ato ilícito.

Art. 187. Também comete ato ilícito o titular de um direito que, ao excedê-lo, excede manifestamente os limites impostos pelo seu fim econômico, social, pela boa-fé ou pelos bons costumes.

Nesse sentido, quando estamos diante de um ato ilícito envolvendo danos morais decorrentes de uma situação derradeira, como a inscrição do nome do indivíduo em instituições financeiras, é possível entender sua aplicação. Entretanto, com a expansão do uso da tecnologia, o direito precisou observar o cometimento do ato ilícito na Internet.

Com o advento da Internet e a criação das redes sociais, que possuem como objetivo ampliar a comunicação entre os indivíduos, houve também o aumento da liberdade de expressão, com o consequente fluxo de informações sem o devido cuidado em questões relacionadas à privacidade das pessoas, criando o mito da Internet como "terra sem lei". 
As redes sociais sempre foram utilizadas para a comunicação entre grupos de pessoas, seja por publicações ou pelos próprios chats de bate-papo. Embora algumas informações sejam obrigatórias, como o nome, o usuário possui a liberdade quanto as postagens, conforme goste ou não de expor a sua privacidade.

\footnotetext{
Numa acepção comum, o "direito de expressar a opinião" é a possibilidade de realizar todos os atos que se subsumam a esta locução. Juridicamente, no entanto, falar-se em um "direito de expressar a opinião" é aludir, implicitamente, à possibilidade de realização garantida de uma série de atos tendentes expressão da opinião, nos limites atributivos das regras de direito, ou seja, desde que tais atos não sejam proibidos por alguma norma jurídica [...] (JORDÃO, 2009, p.8-9).
}

$\mathrm{O}$ direito à privacidade encontra-se explícito no texto constitucional, conforme o artigo $5^{\circ}$, inciso $\mathrm{X}$, sendo relacionado à intimidade pessoal, bem como relacionado ao artigo 21 do Código Civil. Certos autores entendem uma diferenciação entre o direito à intimidade do direito à privacidade. Nesse sentido, a privacidade seria uma esfera mais ampla a qual abarca atos e informações referentes a todas as relações pessoas e profissionais do indivíduo, enquanto a intimidade estaria inserida na privacidade, ou seja, seria mais restrita, referindo-se a relações mais próximas como familiar e afetivas (MENDES; COELHO; BRANCO, 2008, p. 377).

A doutrina encontra diversas divergências quanto ao conceito de privacidade, em alguns momentos se mostrando muito restritiva e em outros abrangentes. De acordo com Leonardi (2011, p. 52), observando os diversos conceitos produzidos pela doutrina e jurisprudência, a privacidade pode ser enquadrada em quatro categorias: a) o direito de ser deixado só; b) o resguardo contra interferências aleias; c) segredo ou sigilo; d) controle sobre informações e dados pessoais.

Quando se trata da privacidade na Internet, há de se ter em mente que é um ambiente que gera a possibilidade de expressar ideias sobre conteúdos, sem restrição, para pessoas em escala mundial. Dessa forma, as redes sociais são consideradas o principal ambiente da liberdade de expressão, visto que não exigem comprovação científica sobre opiniões emitidas e podem ser publicadas a qualquer hora.

Atualmente, a Internet é comumente utilizada para falar de terceiros, seja para expressar uma opinião sobre a pessoa, seja para imputar um fato praticado por esta a qual presenciou, ou mesmo um fato praticado contra si. A partir disso surge a questão: a exposição do outro nessa situação seria considerado um ato ilícito?

Sob esse entendimento, observados os artigos 186 e 187, entende-se que o dano moral causado pelo uso do nome de terceiros nas redes sociais pode sim causar danos civis reparáveis aos terceiros. Não significa que todo Exposeds será, necessariamente, um ato ilícito. Somente o serão aqueles que transbordarem dos limites do exercício regular de direito. A narrativa de fatos, sem menção a terceiros, sem contextualização específica ou qualquer outro traço identificatório, em tese e a princípio, não é considerado abuso. Partindo dessa compreensão, a partir de que ponto o Exposed configuraria abuso de direito?

A sanção contra quem, de fato, pratica um ato ilícito relacionado a outrem é expressa no artigo 927 do Código Civil, o qual estabelece que "aquele que, por ato ilícito (arts. 186 
e 187), causar dano a outrem, fica obrigado a repará-lo”. Nesse sentido, importa ressaltar que a liberdade de expressão pode ser ofensiva por duas perspectivas: a) de conteúdo, como, por exemplo, apologia ao crime; b) de forma, por exemplo, exposição da ofensa em Outdoor em praça pública.

Feita essa breve introdução acerca da liberdade de expressão na Internet, é necessário prosseguir ao debate acerca do abuso de direito, pois como bem descreve NETTO (2015, p. 183) "trata-se de conceito pouco simpático ao individualismo, pois traduz uma ideia de convivência razoável entre as situações jurídicas".

Isso porque o abuso de direito se caracteriza quando o sujeito está na prática do seu regular direito, mas acaba por extrapolar a finalidade da norma (NETTO, 2015, p.184) ou seja, acaba excedendo os limites legalmente estabelecidos, seja para seu fim econômico, social, de boa-fé ou pelos bons costumes. Portanto, na ocorrência do abuso de direito, o indivíduo aparenta estar agindo no regular exercício do seu direito, mas acaba por violar os valores que fundamentam a prática desse mesmo direito (CARPENA, 2003, p. 381).

Para além disso, "o ato abusivo, então, é aquele que, não apenas causa danos a outrem, mas se torna reprovável por infringir deveres morais de justiça, equidade e humanidade, os quais existem acima do plano da legalidade" (CARPENA, 2003, p. 379)".

Para GUERRA (2007, p. 318), o abuso de direito possui enquanto origem a resistência em defender seu direito (por parte do titular desse direito) contra a parte que se excede na prática de seu direito. Na visão do autor, o que ocorre é a ausência de proporcionalidade na prática do direito em relação as demais partes envolvidas.

\footnotetext{
Temos, portanto, segundo a lei civil, dois conceitos de ato ilícito: um no art. 186 e outro no art. 187. Cada espécie tem os seus pressupostos. Para que tenhamos abuso de direito, haveremos de verificar, no caso concreto, se estão atendidos os requisitos do art. 187, sendo impertinente, a propósito, exigir a presença dos requisitos do art. 186. Se assim não fosse - isto é, se para a configuração do abuso do direito tivessem de concorrer os pressupostos do art. 186 -, tornar-se-ia inútil o art. 187 (NETTO, 2015, p. 184).
}

A definição geral de abuso de direito, contudo, não dispensa o entendimento sobre seus dois requisitos de concretização: violação funcional e excesso manifesto. Isso porque a violação funcional opera sobre a boa-fé, a função social, a função econômica e/ou os bons costumes. Já, por seu turno, o excesso manifesto é a métrica utilizada para definir quando um direito deixa de sê-lo para tornar-se abuso.

Nesse sentido, o abuso de direito configura-se quando a parte, praticando seu direito de livre manifestação acerca do ocorrido, expõe informações íntimas, extrapolando a finalidade do direito que busca praticar, ou, melhor dizendo, o abuso está na forma como a liberdade de expressão é exercida, excedendo a função social da livre manifestação.

Como anteriormente descrita, a prática de Exposed normalmente ocorre de duas formas: a) com a exposição do fato e do(s) autor(es) ou b) com a exposição do fato e a ausência de informações sobre o(s) autor(es). Partindo da hipótese de que essa prática busca expor o comportamento inadequado do sujeito e não tão somente o sujeito em si, percebe-se 
que uma vez que o relato oculte informações diretas acerca do autor do ato (como nome, endereço e afins) o ato fica protegido no direito de liberdade de manifestação.

Nesse sentido entende-se que a prática do movimento permite que seja efetivado seu fim, de forma a acolher as vítimas dos fatos, enquanto elas optam por não tornar pública efetivamente a autoria dos fatos expostos, sem incorrer na violação dos direitos das partes.

\section{CONSIDERAÇÕES FINAIS}

Este trabalho foi desenvolvido com o objetivo de compreender no que consiste a prática de Exposed e de quais possíveis formas ela pode configurar-se em abuso do direito ou crime. No decorrer da pesquisa, observou-se que o Exposed é uma prática de discurso expositivo que compreende acontecimentos relevantes à parte que está praticando tal ato, podendo ser realizado por terceiro alheio ao fato. Ademais, é uma prática que ganhou visibilidade recentemente nos meios digitais, na qual a parte que busca expor a conduta de outra(s) parte(s) instiga o tribunal da Internet a ter conhecimento do ocorrido por meio do seu relato.

Ainda, concluiu-se que a instantaneidade das respostas obtidas nas redes sociais impossibilita a prática do contraditório e da ampla defesa, dificultando o desenvolvimento de diálogo entre as partes e ocasionando, em certos casos, o linchamento virtual do sujeito exposto acompanhado de discursos de ódio.

Por conseguinte, observou-se que a prática de Exposed pode ocorrer de basicamente duas formas: por meio do destaque à narrativa ou por meio da imputação ao sujeito que praticou o ato. Isso evidencia que a essência dessa prática localiza-se na descrição do acontecimento e não necessariamente no destaque do autor do fato. Nesse mesmo sentido, como já mencionado, não há impedimentos que um terceiro alheio ao acontecido exponha na Internet o corrido, o que sustenta a tese de que a prática de Exposed tem enquanto foco a descrição dos fatos em si.

No tocante à segunda parte da problemática, a questão levantada trata-se das possíveis práticas de Exposed e quais dessas configurariam abuso de direito. Desse modo, entende-se que, uma vez que a exposição opte por não relevar informações diretas relacionadas ao autor do fato, não se verifica a ocorrência de abuso de direito. Isso porque o abuso configura-se quando a prática do direito (exposição do acontecimento), a parte que exerce seu direito de livre manifestação acerca do ocorrido, expõe informações íntimas, extrapolando a finalidade do direito que busca praticar, ou seja, o abuso está na forma como a liberdade de expressão é exercida.

Dito isso, conclui-se que é possível praticar Exposed nas redes sociais sem incorrer em abuso de direito, resguardando informações íntimas acerca do autor dos fatos, mantendo o foco na descrição do ocorrido e permitindo a ocorrência de diálogo nas redes sociais. Dessa forma, agindo como um movimento que acolhe as possíveis vítimas sem que essas sofram consequências judiciais. 


\section{REFERÊNCIAS}

BBC. O que a campanha \#MeToo conseguiu mudar de fato? 2018. Disponível em: https: // www.bbc.com/portuguese/geral-44164417. Acesso em: 24 mar. 2021.

BRASIL, Constituição Federal. Brasília: Senado Federal, 1988. Disponível em: http:// www.planalto.gov.br/ccivil_03/Constituicao/Constituiçao.htm. Acesso em: 12 mar. 2021.

BRASIL. Lei n ${ }^{\circ} 10.406$, de 10 de janeiro de 2002. Institui o Código Civil. Diário Oficial da União: seção 1, Brasília, DF, ano 139, n. 8, p. 1-74, 11 jan. 2002. PL 634/1975.

CARPENA, Heloisa. A parte geral do novo código civil: estudos na perspectiva civil-constitucional. Coord. Gustavo Tepedino, 2 ed., p. 377-396, Rio de Janeiro: Renovar, 2003.

EL PAÍS. \#MeuAmigoSecreto, nova investida feminista contra o machismo velado. 2015. Disponível em: https://brasil.elpais.com/brasil/2015/11/25/politica/1448451683 866934 . html. Acesso em: 20 mar. 2021.

EL PAÍS. Como o Me Too mudou Hollywood com mulheres famosas e poderosas. 2019. Disponível em: https://brasil.elpais.com/brasil/2019/10/24/internacional/1571945213 631882.html. Acesso em: 28 mar. 2021.

GALILEU. 20 relatos da hashtag \#meuamigosecreto que precisam ser lidos. 2015. Disponível em: https://revistagalileu.globo.com/blog/buzz/noticia/2015/11/20-relatos-da-hastag-meuamigosecreto-que-precisam-ser-ligos.html. Acesso em: 28 mar. 2021.

GUERRA, Alexandre Dartanhan de Mello et al. Responsabilidade Civil por abuso do direito. 2007. Disponível em: https://tede2.pucsp.br/handle/handrle/7525. Acesso em: 15 jul. 2021.

JORDÃO, Eduardo Ferreira. O abuso de direito como ilicitude cometida sob aparente proteção jurídica. 2009. Revista Baiana de Direito, v.4, p.255-292. Disponível em: https:// bibliotecadigital.fgv.br/dspace/handrle/10438/19187?locale-attribute=en. Acesso em: 08 abr. 2021.

LEONARDI, Marcel. Tutela e privacidade na Internet. São Paulo, Editora Saraiva: 2011.

MENDES, Gilmar Ferreira; COELHO, Inocêncio Mártires; BRANCO, Paulo Gustavo Gonet. Curso de Direito Constitucional. $2^{\mathrm{a}}$ ed. São Paulo: Saraiva, 2008.

NETTO, Felipe Peixoto et al. Curso de direito civil: Responsabilidade civil. 2015. 
NADER, Paulo. Curso de direito civil: responsabilidade civil. $6^{\mathrm{a}}$ ed. Rio de Janeiro: Forense, 2016.

SCOTTINI, Alfredo. Minidicionário escolar português-inglês-português, p.235. Blumenau/SC: Todolivro Editora, 2009.

SILVA, Rosane Leal da; VIEIRA, Ingra Etchepare. O MOVIMENTO "EXPOSED” NO CONTEXTO DA SOCIEDADE EM REDE: tensões entre as narrativas de abusos sofridos por internautas e o direito ao esquecimento dos supostos ofensores. In: VERONESE, Josiane Rose Petry et al (org.). DIREITOS HUMANOS E VULNERABILIDADES. Habitus, 2020. p. 1-251. Disponível em: https://portaliedf.com.br/wp-content/uploads/2020/12/ EBOOK-PDF-final-155x225mm-170-DIREITOS-HUMANOS-E-VULNERABILIDADES.pdf. Acesso em: 20 mar. 2021.

UOL. Movimento \#Exposed: mulheres expõem casos de assédio e estupr no Twitter. 2020. Disponível em: https:/www.uol.com.br/universa/noticiais/redacao/2020/06/01/elas-se-calaram-agora-expoe-casos-de-assedio-e-estupro-no-twitter.htm. Acesso em: 26 mar. 2021.

VEJA. Você sabe o que é o movimento \#MeToo? 2019. Disponível em: https://veja.abril. com.br/ideos/veja-explica/voce-sabr-o-que-e-o-movimento-metoo-veja-explica/. Acesso em: 25 mar. 2021.

\section{DAdOS DOS AUTORES}

\section{Driane Fiorentin}

Graduanda em Direito pela Faculdade Meridional (IMED), Passo Fundo, Rio Grande do Sul. E-mail: driane_morais@hotmail.com

\section{Francielli Bressan}

Graduanda de Direito pela Faculdade Meridional IMED - Passo Fundo, Rio Grande do Sul. E-mail: francielli_b@hotmail.com

\section{IURI BOLESINA}

Doutor e Mestre em Direito pela Universidade de Santa Cruz do Sul, UNISC. Especialista em Direito Civil pela Faculdade Meridional, IMED. Graduado em Direito pela Universidade de Passo Fundo - UPF. E-mail: iuribolesina@gmail.com

Submetido em: 4-5-2021

Aceito em: 7-10-2021 